\title{
Design e sociedade: uma reflexão sobre acessibilidade, interação e inclusão
}

\section{Design and society: a reflection on accessibility, interaction and inclusion}

\author{
Willian Amphilóquio ${ }^{1}$ \\ João Eduardo Chagas Sobral ${ }^{2}$
}




\section{Resumo}

Este artigo tem como propósito apresentar as características que tornam o design um campo significativo no tocante à inclusão social. Indivíduos com deficiências enfrentam diariamente problemas de locomoção, de percepção e de interação com o meio em que vivem. A partir de uma metodologia experimental, por meio da revisão de materiais bibliográficos, procurou-se evidenciar, portanto, técnicas e tecnologias pertinentes para o avanço da inclusão. Para tanto, foram abordados alguns fenômenos sociais, culturais, econômicos e políticos que influenciam consideravelmente o trabalho de um designer, a fim de explicitar os limites e enfrentamentos do campo.

Palavras-chave: design; inclusão; tecnologia.

\section{Abstract}

This article aims to present features that make design a significant field in social inclusion. Individuals with disabilities face daily problems of locomotion, perception and interaction with the environment in which they live. From an experimental methodology, through the review of bibliographical materials, it was tried to evidence, therefore, techniques and technologies pertinent to the advancement of the inclusion. In order to do so, some social, cultural, economic and political phenomena that considerably influence the work of a designer were discussed, in order to make explicit the limits and confrontations of the field.

Keywords: design; inclusion; technology.

ISSN: 2316-7963

${ }^{1}$ Mestrando em Design, Univille (willian.amphiloquio@gmail.com)

${ }^{2}$ Doutor em Design, Univille (sobral41@gmail.com) 


\section{Introdução}

A sociedade é formatada por meio de processos culturais que definem as convenções de produção e normas vigentes. Esses aspectos influenciam consideravelmente os comportamentos da população, que, por sua vez, segue um ritmo quase que ininterrupto de conformismo. Entre o passado de grandes revoluções e um futuro de inovações, há questionamentos latentes na malha social a serem trabalhados.

Os novos desafios tecnológicos, principalmente em razão da quarta revolução industrial, prometem trazer benefícios significativos a uma parcela da população que se vê, de certa forma, negligenciada em muitos projetos (SCHWAB, 2016). Esse é o caso de indivíduos com deficiências, enfermos, dentre outros, que enfrentam diariamente situações embaraçosas e frustrantes ao interagir com o ambiente e as pessoas à volta (BRIAN, 1997).

Este artigo preocupa-se em entender o design como um campo importante no processo de inclusão, justamente por seu caráter interdisciplinar. Para tanto, aborda aspectos culturais, econômicos, políticos, tecnológicos e sustentáveis como forma de explicitar as necessidades da população e a atuação do designer como agente de mudança.

De início, a abordagem foca-se na sociedade e no design de um modo geral, evidenciando as implicações dessa relação. Reserva-se a este tópico, também, uma análise sobre o designer como produtor social, bem como o entendimento da área. Ademais, o propósito foi analisar puramente a sociedade e suas percepções e comportamentos, de modo a expor os processos de estruturação e significação de seu corpo. Por fim, apresenta-se o design como viabilizador da inclusão, buscando concentrar os esforços nas técnicas, produções e pesquisas para esse objetivo.

\section{A sociedade e o design}

O design é um campo importante para o desenvolvimento da sociedade, abrangendo aspectos tecnológicos, culturais e econômicos. É sabido que tudo que é gerado em uma sociedade produz impactos na estrutura comportamental e perceptiva da população. Os enfrentamentos de seus agentes são, de certa forma, moldados de maneira a seguir determinadas convenções.

Assim como outros campos de trabalho e inovação, o design está imerso em uma cultura que varia de local para local, e seus resultados de trabalho têm como primazia os aspectos genéricos de desejo em uma sociedade, com foco na criação de objetos voláteis e, de certa forma, frívolos. Às vezes, esses profissionais atentam-se demasiadamente a seus conhecimentos e técnicas, e esquecem-se do ponto principal, as reais necessidades da sociedade.

Wolff $(1981$, p.23) advoga que tudo o que é produzido pela população está sistematicamente localizado em estruturas sociais e, consequentemente, os desejos individuais de cada indivíduo são afetados por esse processo. Desse modo, pode-se considerar a importância de compreender os aspectos que constroem e desenham o fluxo social. Assim, a economia, a tecnologia e a política são campos que determinam 
e em certos momentos sugerem o que deve ser produzido, independente do desejo do designer. Ainda de acordo com a autora, a atividade prática e a criatividade não podem ser separadas e estão fortemente ligadas às estruturas sociais.

Bonsiepe (2011) também compartilha do mesmo pensamento, e explicita que o design tornou-se efêmero ao longo do tempo, adotando para sua área princípios do obsoletismo rápido - ou seja, o consumo rápido -, ideias estético-formais e a glamourização de todo o leque de objetos produzidos. Consequentemente, isso levou o designer, de modo geral, a se distanciar consideravelmente da real intenção da área: a solução inteligente de problemas. Desse modo, evidencia-se como este profissional não trabalha de modo independente. A indústria, os empresários, as pessoas e a economia têm papel crucial no que diz respeito à criação e à produção de produtos. Bonsiepe (2011, p. 29) afirma que: "a contradição mais forte à qual a atividade projetual está exposta jaz na distância entre o que é socialmente desejável, tecnicamente factível, ambientalmente recomendável, economicamente viável e culturalmente defensível".

Ocorre que o foco no consumo acelerado pode não permitir ao designer o engajamento no desenvolvimento de projetos acessíveis. De modo geral, a efemeridade, atrelada à moda, faz o designer criar para públicos genéricos, esquecendo da heterogeneidade do perfil da população. Embora exista necessidades comuns, há sempre aquelas que não são levadas em consideração por contemplarem um público que é comumente enquadrado como minoria. Como propriamente dito, não apenas as necessidades das pessoas devem ser consideradas, mas os recursos econômicos e políticos afetam esse cenário. A importância de produzir um material adaptado, de modo a atender as mais variadas necessidades, pode partir do designer, justamente por este reconhecer o ponto latente a ser trabalhado; todavia, há inúmeras barreiras que este indivíduo irá se deparar, afetando o seu modo de fazer e projetar.

Em contrapartida, o designer como agente de inovação social pode também provocar rupturas significativas na cultura, inclusive criar novas necessidades e comportamentos. Forty (2007, p.12) argumenta que o design "pode dar formas tangíveis e permanentes às ideias sobre quem somos e como devemos nos comportar". Para isso, o designer se utiliza de alguns princípios que são fatores de potenciais discussões sobre o entendimento da área. Para ele, na linguagem cotidiana, o design é dividido em duas perspectivas: a primeira enfoca-se nas questões atreladas ao gosto, à aparência e às noções de beleza de um determinado artefato. A segunda, por sua vez, é limitada por regras e instruções de produção. Ele destaca, no entanto, que por mais que os profissionais da área tentem fazer julgamento de separação desses termos, o entendimento de design abrange ambos os princípios, o que não permite tratá-los de modo independente.

Cipiniuk (2014) faz uso da mesma reflexão sobre o significado do que é efetivamente design, mas acrescenta um, que julga ser de grande valia e importância para a área. Em sua comparação, há três noções do design: a carismática, a funcionalista e, por fim, a social. A visão carismática é mais idealista e caracteriza-se por seu forte apelo ao emocional, explorando aspectos que parecem transcender a realidade. A aparência, pautada em termos como beleza e graça, é trabalhada como meio de 
tornar o objeto especial e, assim, diferenciá-lo dos demais. A visão funcionalista, por sua vez, prega que a forma precisa seguir a função dos artefatos, ou seja, a beleza de um objeto é definida por sua funcionalidade. Desse modo, sua busca enfoca-se em resolver os problemas que estão atrelados ao uso de um artefato. Essa também é a vertente que mais se aproxima da área científica, justamente por apontar uma metodologia funcional e sugerir estudos e padrões para produção. Para os funcionalistas, a estética é utilizada como fórmula harmônica, apoiada na psicologia da forma, conhecida como Gestalt. O valor de uso, para este caso, garante a existência do objeto. Por fim, a visão do design como produção social é abordada pelo autor como uma tentativa de desmistificar os princípios que muitas vezes servem de entrave para a área. Em sua ótica, o designer tende a se utilizar de uma espécie de idealismo para justificar seu trabalho, além de se autoafirmar como portador de uma capacidade inata sensível aos aspectos relacionados ao design - como o entendimento de formas, grafismos, entre outros.

Bonsiepe (2011) evidencia, de igual modo, essa característica quase egoísta da figura do designer, ao discutir sobre o fato de se dar tanta atenção ao design de autor. De acordo com essa percepção, o enfoque demasiado no indivíduo faz com que o real sentido se perca, que é, por sua vez, satisfazer as necessidades latentes na sociedade. Quem compartilha desse mesmo pensamento é Forty (2007, p. 321), ao apontar que "a história da arquitetura e do design está cheia de tentativas de dar sentido a edificações e objetos por meio das carreiras, ideias e teorias de designers conhecidos".

Em resumo, o designer não atua sozinho ao desenvolver um produto. Os fatores culturais e seus julgamentos e normas definem o desenho de um artefato. Assim, no próximo tópico, tem-se como objetivo discutir a respeito dos gostos e dos limites na sociedade.

\section{Aspectos sociais e suas relações comportamentais}

O meio em que a população está inserida socialmente, revela, geralmente, seus comportamentos. Em países considerados de primeiro mundo, em que a renda da população é consideravelmente elevada, por exemplo, os indivíduos tendem a adotar exigências peculiares, como ida aos cinemas e teatros com freqüência, leitura de livros, viagens, entre outros. Se o recorte for feito em uma região menos favorecida e com altos índices de vulnerabilidade social, os comportamentos passam a ser diferentes. A cultura que se constrói, em boa parte dos casos, está atrelada às condições existentes, tais como tecnologia, política e economia.

Com o crescimento das tecnologias e, principalmente, com um cenário de pós-guerra, a partir de 1950, houve a necessidade de se alavancar a economia. Desse modo, começaram a surgir na época, principalmente nos Estados Unidos da América - EUA, novos produtos que prometiam facilitar o cotidiano das famílias. A partir desse exemplo, observa-se que o design foi crucial para a manutenção e propagação desses produtos, permitindo o crescimento econômico local. Todavia, embora isso também seja verdade, não se pode olhar apenas por meio dessa única perspectiva. Três fatores foram determinantes para a criação de tais objetos: a sociedade, por 
meio de suas necessidades; a economia, que precisava crescer; e as tecnologias, que permitiram tangibilizar as ideias (BORDIEU, 2008; FORTY, 2007).

Assim, quando observa-se um determinado artefato, há nele uma história que às vezes pode passar despercebida. O material, o estilo e sua forma estão intimamente ligados às tendências e à economia vigente em que foi produzido. Segundo Becker (2009, p.27): "a concentração no objeto desvia nossa atenção para as capacidades formais e técnicas de um meio". Desse modo, o foco puramente no autor ou no resultado do material pode, equivocadamente, excluir todos os meios que permitiram o desenvolvimento de tal produto. Ainda de acordo com o autor, tudo o que um meio pode produzir está interligado às limitações organizacionais que, por sua vez, podem afetar consideravelmente o uso do artefato.

Segundo Forty (2007), o principal objetivo em uma sociedade coberta pelo sistema capitalista é o lucro. Ou seja, embora o designer acredite que todo o processo projetual seja para dar expressão à criatividade e à imaginação, o verdadeiro propósito é que o produto alcance os maiores resultados de vendas possíveis. A situação econômica e seu sistema, portanto, são fatores determinantes para a criação de artefatos. Esse é um dos limitantes quando se diz respeito à construção e desenvolvimento de produtos voltados à inclusão, porque, no geral, demandam mais custos e materiais. Para evitar que esses projetos de caráter inclusivo sejam barrados em função do sistema, faz-se importante investir-se em tecnologias e em inovação, de modo a diminuir as fronteiras entre acessibilidade e viabilidade.

Além da economia, outro fator determinante está atrelado ao gosto na sociedade, ou seja, o modo pelo qual as pessoas se relacionam com os objetos e os percebem. De acordo com Bordieu (2008, p.9): "as maneiras de adquirir sobrevivem na maneira de utilizar as aquisições". Assim, o significado de um produto é compreendido por meio das convenções sociais. O gosto, nesse caso, é um marcador de classes, isto é, a população, de um modo geral, é ensinada a se comportar e a entender o mundo a partir do que lhe é oferecido, o que lhe confere gostos diferentes - refinados ou não. Assim, seja qual for a necessidade - o que entende-se como práticas culturais e preferências -, ela foi construída, é produto da educação e está intimamente ligada, em primeiro lugar, ao nível de instrução e, em segundo, à origem social. Nesse sentido, o belo para um pode ser feio para outro, bem como o entendimento de certo ou errado. Esse é o mesmo motivo que faz com que as pessoas apreciem uma obra de arte de um pintor famoso. Mas se essa obra fosse levada a um local cuja cultura de difere consideravelmente, como a indígena, as percepções sobre a obra iriam variar.

Bordieu (2008) cunhou a teoria dos campos, na qual os processos simbólicos formatam a estrutura da sociedade. Esta, por sua vez, cria as culturas e, consequentemente, o habitus, que essencialmente são os processos já absorvidos e reproduzidos pela população. Isso tudo, como propriamente dito, é ensinado e passado para cada indivíduo por meio da educação. Cada campo pode influenciar o outro, mas o seu limite vai até o ponto em que seus efeitos podem ser alcançados. Esses campos são compostos por agentes que podem causar a mudança de habitus e, assim, alterar a estrutura do campo. Os grandes avanços voltados à sustentabilidade, principalmente no que diz respeito à poluição e desmatamento, por exemplo, são trabalhados por 
pessoas que se engajam por essas causas, ou seja, são estes agentes de mudança no campo em que estão situados.

O que se pode perceber, portanto, é que além de qualquer necessidade ou desejo, há um motivo implícito que se faz importante conhecer e entender. Desse modo, ao compreender estes aspectos, o olhar sobre o real problema se faz mais assertivo. No próximo tópico, buscou-se abordar as tecnologias e técnicas que ajudam a construir um cenário inclusivo.

\section{O progresso do design inclusivo}

Desde o período da primeira revolução industrial, com a máquina à vapor, à quarta revolução industrial, com a chegada da internet das coisas, o mundo evoluiu consideravelmente no entendimento sobre a necessidade das máquinas e sua relação com as pessoas. Schwab (2016) argumenta que o termo 'revolução' evoca uma transformação radical e abrupta, e explicita que essas revoluções aconteceram com o surgimento de novas tecnologias e novas maneiras de perceber o mundo. Isso provoca uma ruptura nos modos convencionais da sociedade e da economia, desencadeando profundas mudanças.

O design, no decorrer da história, sofreu importantes mudanças que alteraram o seu modo de projetar e de entender a sociedade. Sua preocupação deixou de ser apenas industrial e passou a ganhar novas modelagens, como o design participativo, o design thinking, o design sustentável e o design centrado no humano. São aberturas significativas para a promoção de uma sociedade inclusiva.

Essas mudanças desencadearam novos estudos e muitos outros foram adaptados, como a acessibilidade. De acordo com Lidwell et al. (2003, p.14), em tradução livre: "o princípio da acessibilidade prega que o design precisa ser usável por pessoas de diversas habilidades, sem uma adaptação ou modificação especial". Especialmente no design, no decorrer da história, a acessibilidade teve importância no que diz respeito às pessoas com deficiência, e foi este o foco principal. No entanto, conforme foi crescendo e ganhando corpo teórico e prático, o foco no desenvolvimento de projetos se expandiu e passou a abranger diversos aspectos, com a intenção de beneficiar a todos, e não apenas quem portasse algum tipo de deficiência. Há 4 características que servem de base para estruturar e desenvolver um projeto com o foco na acessibilidade: a perceptibilidade, quando o design pode ser percebido além das habilidades sensoriais; a operabilidade, quando o design pode ser usado além das habilidades físicas; a simplicidade, quando o design pode ser facilmente entendido e usado além da experiência do indivíduo; e o perdão, quando a incidência de erros é minimizada. A premissa do design acessível, portanto, é a de evitar desconfortos, prevenir erros e facilitar a vida de todos, independente de seu nível de instrução e habilidade de qualquer espécie.

Nessa perspectiva, destacam-se as metodologias do design centrado no humano, o design thinking e o design participativo, que compartilham quase que do mesmo pensamento, mas apresentam estruturas e objetivos específicos. Estão enquadrados no que se chama de novo design (pós-design), vertente que busca ex- 
plorar as habilidades projetuais do design, tornando-o ainda mais interdisciplinar. Em resumo, as três principais ferramentas citadas definem-se do seguinte modo: o design centrado no humano busca entender as reais necessidades das pessoas e suas peculiaridades para, então, desenvolver algo (NORMAN, 2006); o design thinking tem como propósito a busca por soluções focadas na empatia, aperfeiçoando o entendimento de processos e produtos (VIANNA et al, 2012); e o design participativo, cuja proposta enfoca-se na colaboração do público e dos demais participantes no processo projetual (ROSA \& MORAES, 2012).

Estas ferramentas, de um modo geral, são potenciais recursos para a construção de produtos e serviços voltados à inclusão, uma vez que apresentam como fator determinante as necessidades das pessoas. Desse modo, busca-se minuciosamente averiguar os comportamentos e as exigências peculiares, a fim de tornar o projeto viável e assertivo. Antes, a ideia de projetar afastava-se da população, ou seja, seu resultado se dava a partir de uma imposição - daí a dificuldade e o distanciamento de indivíduos com deficiências ou com outras necessidades, pois não encontravam nos produtos ou nos ambientes o que precisavam. As percepções mais sutis são de grande importância, pois a partir delas surgem insights, que caracterizam-se como possíveis ideias de projeto. Esses achados desenham o caminho a ser percorrido pelo designer.

O design também apropria-se de outras ferramentas, como a ergonomia, a fim de otimizar a interação entre os seres humanos e as máquinas em seu espaço de trabalho ou de convivência. A importância dessa abordagem enfoca-se na criação de produtos adaptados coerentemente aos comportamentos e posições que um indivíduo produz. Desse modo, por meio da ergonomia, é possível, também, solucionar necessidades latentes daqueles que possuem características incomuns (MORAES, 2009).

A Pesquisa Nacional de Saúde - PNS 2013 (levantamento de dados focado em indivíduos com deficiências temporárias ou permanentes, progressiva, regressiva ou estável e intermitente ou contínua) revelou que 6,2\% de uma estimativa de 200,6 milhões de brasileiros possuíam pelo menos um dos quatro tipos de deficiências: intelectual, física, auditiva e visual. 1,3\% da população apresenta deficiência física, enquanto os deficientes visuais contam com a maior proporção, 3,6\%. São números significativos e evidenciam um público que ainda sofre com pouca visibilidade. Há também a perspectiva sobre outros tipos de diagnósticos, como a doença de Parkinson, que afeta diretamente os movimentos de uma pessoa (IBGE, 2013).

Em muitos momentos esses indivíduos recorrem a adaptações caseiras, de modo a suprir necessidades pontuais, principalmente quando se diz respeito aos ambientes domésticos. No entanto, quando se parte para locais urbanos e públicos, a situação se difere consideravelmente, dada a falta de estrutura adaptada e poucos recursos.

Já há alguns instrumentos disponíveis no mercado para esses indivíduos, bem como iniciativas e novas sugestões de produtos. No grupo dos mais simples e mais conhecidos podem-se encontrar as cadeiras de rodas, pisos podotáteis, ledores, bengalas, elevadores e rampas. Já no grupo dos mais complexos, há as colheres inteligentes Liftware Level'TM \& Liftware Steady ${ }^{\mathrm{TM}}$ (2017, web), cujo objetivo é facilitar e dar 
autonomia às pessoas com parkinson na hora de se alimentar; e os carros autônomos, como o Google Car, agora chamado de projeto "Waymo" (2017, web), que permitirão com que indivíduos com os mais diversos tipos de deficiências, sejam elas físicas ou sensoriais, possam se deslocar com autonomia para qual for o local que desejem. As tecnologias são fortes aliadas do design e permitem a criação de produtos inovadores, o que, consequentemente, direciona a humanidade para avanços importantes no que diz respeito à inclusão.

Figura 1: Tecnologias voltadas à inclusão

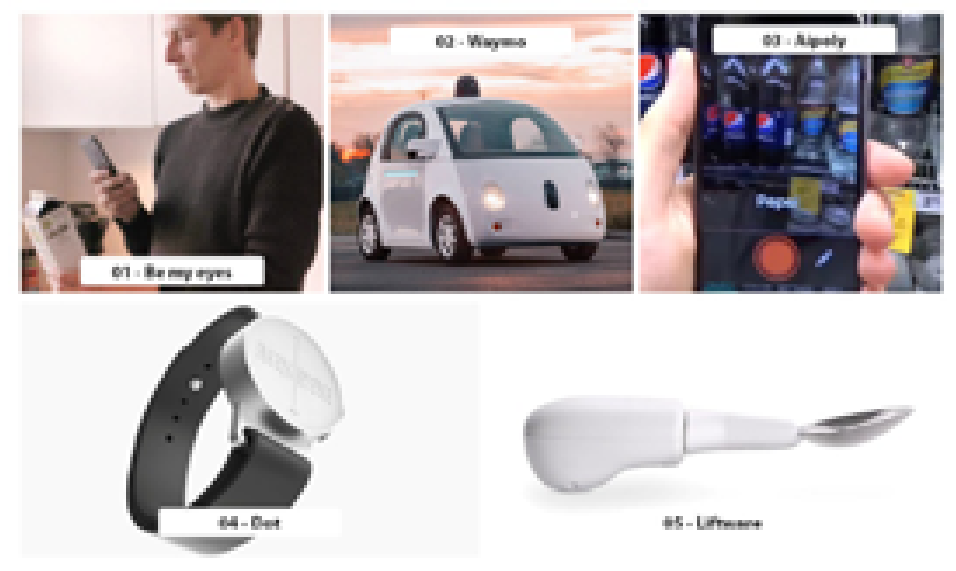

Fonte: vide referências (2017)

A figura 01 apresenta alguns exemplos de tecnologias existentes - ou em processo de estudo. O aplicativo Be My Eyes (2017, web), por exemplo, faz com que o indivíduo cego possa entrar em contato com uma pessoa vidente por meio do celular, e esta última o ajuda a identificar o objeto que deseja. Já o aplicativo Aipoly (2017, web), por sua vez, permite com que o celular reconheça o objeto para o qual a pessoa aponta. O Dot (2017, web) trata-se de um relógio que marca as horas por meio do Braille. Estes produtos, no entanto, muitos deles já disponíveis à população, ainda apresentam valores altos, o que dificulta o acesso, principalmente em países mais pobres.

Como já abordado, nas sociedades capitalistas, o lucro é o fator determinante na venda de um produto. Contudo, os avanços e as pesquisas não param. Um dos enfrentamentos desse sistema ainda é a distância que produz na sociedade. O mundo caminha para uma noção compartilhada de produção e consumo. Os produtos, de acordo com Manzini (2008), serão substituídos por serviços, tais como Uber, AirBnB, Spotify e NetFlix. Os códigos também passarão a ser abertos, como o Linux, e os espaços cada vez mais compartilhados, como as bicicletas de aluguel, já comum em vários países. São apenas exemplos de um futuro compartilhado e conectado, que trarão benefícios para todos, especialmente aos que apresentam algum tipo de deficiência ou dificuldade. Schwab $(2016$, p.21) defende que "a quarta revolução industrial oferece a oportunidade de integrar à economia global as necessidades de 2 bilhões de pessoas, criando demandas adicionais para serviços e produtos existentes, ao capacitar e conectar, umas com as outras, as pessoas e comunidades de todo o 
mundo".

Leitão (2015) pondera sobre o futuro próximo e as mudanças demográficas da população, e comenta, ao apresentar dados consistentes, sobre o empoderamento das pessoas. A programação visual é também algo abordado, e o apelo por mudanças nos pictogramas mais comuns, como o de idosos e o de deficientes, já se faz presente. $O$ modo como ainda esses pictogramas são desenhados já não mais representa essas pessoas. Isso é reflexo de uma sociedade mutável, em constante evolução.

Há ainda embargos políticos, econômicos e culturais, mas, com o tempo e os avanços tecnológicos e científicos, muitas distâncias poderão ser diminuídas. A população encontra-se sob um paradigma sistêmico e ecológico, que tem como fim integrar os mais diferentes conhecimentos e culturas. Essa visão holística permite um olhar abrangente, de modo a entender o todo, para, então, analisar as partes. As culturas híbridas, quando se há a integração ou a fusão de culturas diferentes, podem trazer consideráveis benefícios no que diz respeito ao compartilhamento de informações, de produtos e de serviços (CANCLINI, 2013).

\section{Considerações Finais}

O design está imerso em um complexo sistema social que interfere diretamente em seu modo de projetar. Pôde-se perceber que, independente das vontades de um designer, um produto se constrói por inúmeros fatores, como as tecnologias, a situação e a demanda econômica vigente e, sobretudo, pelo interesse da população.

Observou-se que os processos comportamentais e de julgamento definem a afinidade com que os indivíduos que habitam um determinado espaço se relacionam e interagem, principalmente com os artefatos e a informação que recebem. De modo geral, as pessoas são ensinadas pelo meio em que vivem a aceitar os procedimentos cultivados, o que se entende como convenções sociais.

A partir dessas considerações apresentadas, pôde-se entender a realidade de indivíduos que nascem com necessidades distintas às comumente adotadas. Mais do que isso, o modelo capitalista também ajuda a configurar este cenário que, na maior parte dos casos, negligencia quem não pertence a um padrão.

No entanto, essas fronteiras podem ser quebradas a partir da busca por novas tecnologias e inovações, as quais essencialmente podem trazer benefícios consideráveis e importantes para aqueles que necessitam de produtos com soluções específicas. Desse modo, com o objetivo constante pela otimização de técnicas e princípios, como a acessibilidade, transforma-se uma realidade que é condicionada a comportamentos desiguais.

O design, como área interdisciplinar, utiliza-se dos recursos existes para fomentar e trabalhar de modo respeitoso às diferenças, principalmente no tocante às técnicas e metodologias focadas na empatia (a capacidade de se colocar no lugar no outro), na participação e, sobretudo, no humano.

O tempo presente revela, por meio de estudos e pesquisas, apontamentos pertinentes para o futuro, desde uma simples programação visual, a um sistema inteligente de carros autônomos, que permitirão a autonomia de indivíduos cegos, por 
exemplo. A própria configuração da sociedade, como a sua demografia, deixa pistas sobre as necessidades futuras.

Portanto, o campo do design tem muito a aproveitar desses achados valiosos, para, assim, permitir a construção de uma sociedade inclusiva, compartilhada e conectada.

\section{REFERÊNCIAS}

Aipoly - Vision Through Artificial Intelligence. Disponível em: <http://aipoly.com/ index.ht $\mathrm{ml}>$. Acesso em: 20 de mai. 2017.

AutoWeek. Disponível em: <http://hanabi.autoweek.com/sites/default/files/styles/ gen-932-524/public/front-lights-view-1_0.jpg?itok=PbpiUqUV>. Acesso em: 20 de mai. 2017.

BECKER, Howard Saul. Falando da sociedade: ensaios sobre as diferentes maneiras de representar o social. Rio de Janeiro: Jorge Zahar Editores, 2009.

Bem My Eyes. Disponível em: <http://bemyeyes.com/what-is-be-my-eyes/>. Acesso em: 20 de mai. 2017.

BOURDIEU, Pierre. A distinção: crítica social do julgamento. São Paulo: Edusp; Porto Alegre: Zouk, 2008.

BONSIEPE, Gui. Design, cultura e sociedade. São Paulo: Blusher, 2011.

BRYAN, Jenny. Conversando Sobre Deficiências. São Paulo: Ed. Moderna, 1998. 176 p.

CANCLINI, Néstor García. Culturas Híbridas: estratégias para entrar e sair da modernidade. São Paulo: Editora da Universidade de São Paulo, 2013.

CIPINIUK, Alberto. Design: o livro dos porquês: o campo do design compreendido como produção social. Rio de Janeiro: Ed. PUC-Rio; São Paulo: Ed. Reflexão, 2014.

Dot. Disponível em: <https://dotincorp.com/>. Acesso em: 20 de mai. 2017.

FORTY, Adrian. Objeto de desejo - design e sociedade desde 1950. São Paulo: Cosac Naify, 2007.

LEITÃO, Miriam. História do Futuro: o horizonte do Brasil no século XXI. Rio de Janeiro: Intrínseca, 2015.

LIDWELL, William; HOLDEN, Kritina; BUTLER, Jill. Universal principles of design: a 
cross-disciplinary reference. Gloucester, Massachusetts: Rockport Publishers, 2003. Liftware. Disponível em: <https://www.liftware.com/>. Acesso em: 20 de mai. 2017. MANZINI, Ezio. Design para a inovação social e sustentabilidade: comunidades criativas, organizações colaborativas e novas redes projetuais. Rio de Janeiro: E-papers, 2008.

MORAES, Anamaria de. Ergonomia: conceitos e aplicações. Rio de Janeiro: 2AB, 2009.

MORAES, Ana Maria e SANTA ROSA, José Guilherme. Design Participativo: Técnicas para inclusão de usuários no processo de ergodesign de interfaces. Rio de Janeiro: Rio Books, 2012.

NORMAN, Donald A. O Design do Dia a Dia. Rio de Janeiro: Rocco, 2006.

Pesquisa nacional de saúde: 2013: ciclos de vida: Brasil e grandes regiões / IBGE, Coordenação de Trabalho e Rendimento. Rio de Janeiro: IBGE, 2015.92 p.

SCHWAB, Klaus. A quarta revolução industrial. São Paulo: Edipro, 2016.

VIANNA, Maurício et al. Design Thinking: Inovação em Negócios. Rio de Janeiro: MJV Press, 2012. 162 p.

Waymo. Disponível em: <https://waymo.com/journey/>. Acesso em: 20 de mai. 2017.

WOLFF, Janet. A produção social da arte. Rio de Janeiro: Zahar Editores, 1982. 